\title{
Comparative Study of Bisphenol A Release from Various Orthodontic Adhesive and Myofunctional Appliances - An In-Vitro Study
}

\author{
Chanamallappa R. Ganiger ${ }^{1}$, Sahil Sainath Patil2 ${ }^{2}$, Renuka Pawar³, Sandesh Phaphe ${ }^{4}$, \\ Yusuf Ahammed Ronad ${ }^{5}$, Pratap Mane ${ }^{6}$, Nidhi Rohit Agarwal7 ${ }^{7}$ Tanuja Tanaji Sathe ${ }^{8}$
}

\begin{abstract}
${ }^{1}$ Department of Orthodontics and Dentofacial Orthopaedics, School of Dental Sciences, Krishna Institute of Medical Sciences, Malkapaur, Karad, Maharashtra, India. ${ }^{2}$ Department of Orthodontics and Dentofacial Orthopaedics, School of Dental Sciences, Krishna Institute of Medical Sciences, Malkapaur, Karad, Maharashtra, India. ${ }^{3}$ Department of Orthodontics and Dentofacial Orthopaedics, School of Dental Sciences, Krishna Institute of Medical Sciences, Malkapaur, Karad, Maharashtra, India. ${ }^{4}$ Department of Orthodontics and Dentofacial Orthopaedics, School of Dental Sciences, Krishna Institute of Medical Sciences, Malkapaur, Karad, Maharashtra, India. ${ }^{5}$ Department of Orthodontics and Dentofacial Orthopaedics, School of Dental Sciences, Krishna Institute of Medical Sciences, Malkapaur, Karad, Maharashtra, India. ${ }^{6}$ Department of Orthodontics and Dentofacial Orthopaedics,

School of Dental Sciences, Krishna Institute of Medical Sciences, Malkapaur, Karad, Maharashtra, India. ${ }^{7}$ Department of Orthodontics and Dentofacial Orthopaedics, School of Dental Sciences, Krishna Institute of Medical Sciences, Malkapaur, Karad, Maharashtra, India. ${ }^{8}$ Department of Orthodontics and Dentofacial Orthopaedics, School of Dental Sciences, Krishna Institute of Medical Sciences, Malkapaur, Karad, Maharashtra, India.
\end{abstract}

\section{ABSTRACT}

\section{BACKGROUND}

We wanted to compare \& evaluate, regularly used orthodontic materials including adhesives \& myofunctional appliances for release of Bisphenol A.

\section{METHODS}

Bisphenol - A release was assessed from two materials - orthodontic adhesive resin and heat cure acrylic resin [twin block]. Based on materials used, a total of 40 samples was assigned into two groups; Group A and Group B, each containing 20 samples. For Group A [orthodontic adhesive resin], metal brackets were bonded to 20 bicuspid teeth using adhesive resin and cured with LED light. For group B, 20 twin block appliances made from heat cured acrylic resin were used. Then, samples from both the groups were immersed in artificial saliva and then subjecting to thermal treatment from hot $\left(60{ }^{\circ} \mathrm{C}\right)$ to cold $\left(4^{\circ} \mathrm{C}\right)$ temperatures, followed by shaking for 5 minutes. The samples were again shaken at $\left(37^{\circ} \mathrm{C}\right)$ and $1.0-\mathrm{mL}$ aliquots were removed at 24 hours and 7 days after insertion. Gas chromatography / mass spectroscopy was used for the evaluation of leaching of bisphenol A from artificial saliva.

\section{RESULTS}

Significant results were found after 24 hours of analysis in both groups where $70 \%$ samples from group A had bisphenol A release, whereas $80 \%$ samples from group B had bisphenol A release. However, a non-significant result was obtained after 7 days where $20 \%$ samples from group A had bisphenol A release whereas $60 \%$ samples from group B had bisphenol A release. The Heat cure acrylic group showed higher Bisphenol - A than that of orthodontic adhesive resin group. It was seen that the levels were lower than the reference dose which were calculated for daily consumption but were statistically significant.

\section{CONCLUSIONS}

Bisphenol A is considered as an endocrine disruptor. Degradation of orthodontic materials results in leaching of Bisphenol-A into oral cavity which is a clinical concern.

\section{KEY WORDS}

Bisphenol-A, Adhesive Resin, Acrylic Resin, Orthodontics
Corresponding Author:

Dr Sahil Patil.

Depatment of Orthodontics

and Dentofacial Orthopaedics,

School of Dental sciences,

Krishna Institute of Medical Sciences,

Malkapaur, Karad - 415510,

Maharashtra, India.

E-mail: docsahilpatil@gmail.com

DOI: $10.14260 / \mathrm{jemds} / 2020 / 564$

How to Cite This Article:

Ganiger CR, Patil SS, Pawar R, et al. Comparative study of bisphenol-A release from various orthodontic adhesive and myofunctional appliances - an in vitro study. J Evolution Med Dent Sci 2020;9(36): 2593-2596, DOI:

10.14260/jemds/2020/564

Submission 17-05-2020,

Peer Review 31-07-2020

Acceptance 06-08-2020,

Published 07-09-2020.

Copyright (C) 2020 JEMDS. This is an open access article distributed under Creative Commons Attribution License [Attribution 4.0 International (CC BY 4.0)] 


\section{BACKGROUND}

Bisphenol-A (BPA) is a synthetic chemical with disruptive endocrine and weak estrogenic properties. BPA is one of the components in polycarbonate and epoxy polymers, which have enormous applications which ranges from paints, coatings, and adhesives to electrical components, and data storage. Over recent decades, there has been extreme growth in the unease about the release of chemicals from various appliances. In 2011, amongst the endocrine disruptive chemicals listed by the World Health Organization, bisphenol A (BPA) was one of them and was considered to be a synthetic compound that has gained medical attention. ${ }^{1}$

BPA release was emphasized by many authors as it was seen that it affects various organs and is known to have teratogenic effects even at a low dose. It results in early onset of puberty, causing feminization in males, and also in association with carcinogenic effects. There were many studies carried out in animals which eventually deduced the BPA presence in body fluids including urine, adult and fetal blood, amniotic fluid, placental tissues, breast milk, and saliva. ${ }^{2,3}$ Epoxy resin and polycarbonate plastic are produced from a synthetic chemical substance called BPA which is highly used for the manufacturing of products such as toys, materials for packaging food, used as resinous material in dentistry for example the pit and fissure sealants and composites, detergents, pesticides and many more. There are many products in the market which are based on epoxy resins and polycarbonate plastics, in turn exposing the BPA to humans. Due to the competitive binding of oestrogen like polymer molecules to natural hormone receptors, the BPA has gained its estrogenic potential, and authors have considered BPA for its endocrine disruptions. There are many routes of exposure to this BPA, like from the environment itself water, air and soil but amongst them the primary source being the foodstuffs. ${ }^{2,3}$

For better treatment outcomes, it is necessary to bond orthodontic brackets with composite materials based on bisphenol A glycidyl methacrylate in patients undergoing orthodontic treatment with fixed appliances. ${ }^{4,5}$ Bisphenol A (2, 2'- bis [4 - hydroxyphenyl] propane; BPA) is considered to be the main component used in resins and orthodontic adhesives. ${ }^{6}$ Composites releases BPA in 2 phases: first phase is during or just after resin placement which is because of deficiency in polymerization of monomer, and the second phase is because of material degardation. ${ }^{6}$ BPA release in the intraoral environment, may be due to the exposure of these materials to extreme thermal changes, mechanical erosion, $\mathrm{pH}$ alterations, and enzymatic degradation from bacterial and salivary enzymes. There are also few facts which suggest the release of BPA as a result of incomplete polymerization of adhesive systems. ${ }^{6}$

The precursors of bisphenol A glycidyl methacrylate (Bis GMA), bisphenol A dimethacrylate (Bis - DMA), and bisphenol A ethoxylated dimethacrylate (Bis - EMA) monomers found in dental sealants, adhesive resins, and composite resins is considered to be BPA in the clinical dentistry. There is a degradation of these materials which takes place in the intra oral environment which in turn leaches BPA, which is of concern and could be affected by temperature changes, mechanical wear, changes in $\mathrm{pH}$, and bacterial or salivary enzymatic action. So, this study was done to compare \& evaluate regularly used orthodontic materials including adhesive \& myofunctional appliances for release of Bisphenol A.

\section{METHODS}

This study was carried out in the Department of Orthodontics and Dentofacial Orthopaedics, KIMSDU, Karad, Maharashtra, India, after obtaining ethical clearance from the university. This in vitro study analysed the presence of Bisphenol-A from various orthodontic materials for different time intervals. This study was conducted on 10 samples in each group. Group A consisted of 10 bicuspid teeth without any fluorosis, caries or fractures. Group B consisted of twin block appliance made of heat cure acrylic resin.

\begin{tabular}{|cc|}
\hline Group & Material \\
Group A & Transbond XT resin adhesive \\
Group B & Twin block appliance (heat cure acrylic resin) \\
\hline & Table 1. Groups in the Study \\
\hline
\end{tabular}

\section{Procedure for Evaluation of Bisphenol A Release from Orthodontic Adhesive}

The Extracted Bicuspids samples were cleaned and the enamel surface were subjected to etching using $37 \%$ Phosphoric acid. On the buccal surface of the bicuspid, Transbond XT primer was applied which was further photo activated for 20 seconds. The bracket base was applied with Transbond XT resin, and were bonded to the teeth, followed by and photo activation for 20 seconds with a LED light-curing unit at $1200 \mathrm{~mW} / \mathrm{cm}^{2}$ light intensity. After that a medium of $10.0 \mathrm{~mL}$ of Artificial Saliva in glass was used for the sample immersion. Samples from the twin block groups were immersed in artificial saliva and then subjecting them to thermal treatment from temperature hot $\left(60{ }^{\circ} \mathrm{C}\right)$ to cold $\left(4{ }^{\circ} \mathrm{C}\right)$ followed by shaking for 5 minutes, the samples were again shaken at $\left(37^{\circ} \mathrm{C}\right)$ and $1.0-\mathrm{mL}$ aliquots were removed at 24 hours and 7 days after insertion. Following this, Gas chromatography/Mass spectroscopy was used for evaluation of leaching of bisphenol A from artificial saliva. ${ }^{7}$

\section{Procedure for Evaluation of Bisphenol A Release from Twin Block}

Samples from the twin block groups were immersed in artificial saliva and then subjecting them to thermal treatment from temperature hot $\left(60^{\circ} \mathrm{C}\right)$ to cold $\left(4^{\circ} \mathrm{C}\right)$ followed by shaking for 5 minutes, the samples were again shaken at $\left(37^{\circ} \mathrm{C}\right)$ and $1.0-\mathrm{mL}$ aliquots were removed at 24 hours and 7 days after insertion. This procedure was repeated for a total of 10 cycles.

\begin{tabular}{|cc|}
\hline Time & Phase of treatment \\
T1 & 24 hours after immersion \\
T2 & 1 week after immersion \\
\hline & Table 2. Sample Evaluation Schedule \\
\hline
\end{tabular}




\section{Statistical Analysis}

Tabulation of data was done followed by statistical analysis after the data was collected. SPSS Software Version 20 was used to perform Statistical analysis. Summary statistics was done using frequency \& percentage. Chi - square test was used to evaluate association among inter-group \& intra - group study variables with demographic variables. Statistical values are significant when $\mathrm{p}<0.05$.

\section{RESULTS}

Qualitative analysis of Group A (Transbond XT) showed that Bisphenol A was present in $70 \%$ samples while absent in 30 $\%$ samples at T1 (24 hrs.). While qualitative analysis of Group A (Transbond XT) at T2 (7 days) showed that Bisphenol A was present in $20 \%$ samples while absent in $80 \%$ samples.

\begin{tabular}{|c|c|c|c|c|}
\hline & \multicolumn{2}{|c|}{ Group A (Trans Bond XT) } & Chi - Square & P - Value \\
\hline & 24 hrs. (T1) & 7 days (T2) & \multirow{4}{*}{3.232} & \multirow{4}{*}{0.0722} \\
\hline Present & $7(70 \%)$ & $2(20 \%)$ & & \\
\hline Absent & $3(30 \%)$ & $8(80 \%)$ & & \\
\hline Total & $10(100 \%)$ & $10(100 \%)$ & & \\
\hline \multicolumn{5}{|c|}{ Table 3. Association of BPA Release from } \\
\hline \multicolumn{5}{|c|}{ Transbond XT at Different Time Intervals } \\
\hline
\end{tabular}

Qualitative analysis of Group B (Twin Block) showed that Bisphenol A was present in $80 \%$ samples while absent in 20 $\%$ samples at T1 (24 hrs.) While qualitative analysis of Group B (Twin Block) at T2 (7 days) showed that Bisphenol A was present in $60 \%$ samples while absent in $40 \%$ samples.

Comparison of Group A and Group B at T1 (24 hrs.) showed significant results of Bisphenol A release. Comparison of Group A and Group B at T2 (7 days) showed non-significant results of Bisphenol A release.

\begin{tabular}{|c|c|c|c|c|}
\hline & \multicolumn{2}{|c|}{ Group B (Twin Block) } & Chi - Square & P - Value \\
\hline & 24 hrs. (T1) & 7 days (T2) & \multirow{4}{*}{3.232} & \multirow{4}{*}{0.0722} \\
\hline Present & $8(80 \%)$ & $6(60 \%)$ & & \\
\hline Absent & $2(20 \%)$ & $4(40 \%)$ & & \\
\hline Total & $10(100 \%)$ & $10(100 \%)$ & & \\
\hline \multicolumn{5}{|c|}{$\begin{array}{l}\text { Table 4. Association of BPA Release from Twin Block } \\
\text { Group at Different Time Intervals }\end{array}$} \\
\hline iffe & $p<0.05$ & & & \\
\hline
\end{tabular}

\begin{tabular}{|ccccc|}
\hline Comparison & Transbond XT & Twin Block & Chi-Square & P-Value \\
Present & $7(70 \%)$ & $8(80 \%)$ & 0.267 & 0.606 \\
Absent & $3(30 \%)$ & $2(20 \%)$ & & \\
\hline \multicolumn{4}{|c|}{ Table 5. Comparison between the Two Materials after 24 hrs. } \\
\hline *significant when $\mathrm{p}<0.05$
\end{tabular}

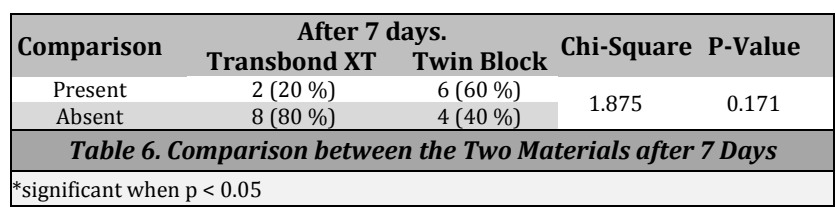

\section{DISCUSSION}

This study explored BPA leaching from routinely employed orthodontic materials which are used from weeks to years. Elevated human BPA levels can cause cancer cell proliferation, peripheral arterial disease, cardiovascular disease, diabetes, abnormal liver enzyme levels, and obesity in children and adolescents.

Composites releases BPA in 2 phases: first phase is during or just after resin placement which is because of deficiency in polymerization of monomer, and the second phase is because of material degradation.

In our study, the Bisphenol-A release from Transbond XT adhesive group was seen in $70 \%$ of the samples after 24 hours and $20 \%$ after 7 days. A similar study was conducted by Marlia Rodrigues Moreira et al where they evaluated Bisphenol A release from orthodontic adhesives for 30 days with gas chromatography. ${ }^{8}$ They concluded that BPA levels at 30 minutes \& 24 hours were significant while at the end of 30 days values were negligible.

The results achieved in the current study depicted significant Bisphenol A release after 24 hours and at the end of 1 week. This was concordant to the results achieved by Matthew W. Kotyk; William A. Wiltshire, where they had evaluated BPA levels from Transbond XT discs immersed in artificial saliva for $1,3,7$, and 14 days and observed BisphenolA leaching only within the first 3 days. ${ }^{9}$ In this study, the Bisphenol-A release from heat cure acrylic was $80 \%$ after 24 hours and $60 \%$ after 7 days respectively. They also said that the Complex polymerization is of utmost importance when it comes to the prevention of BPA leakage from resin-based materials. In the case of the chemically polymerized resin, where oxygen prevents the polymerization over the surface, it is important to wait for hardening of the material and to grind the surface.

Since the visible light has the potential of reaching only a distance of $2 \mathrm{~mm}$ into the material, the usage of optical polymerization-type resin in deep cavities has gained interest of many dentist. Furthermore, there could be a leakage of the bonding agent having an increased levels of monomer as well in turn causing a delayed-type allergic reaction in the tissues. Therefore, the manipulation of the dental materials which contains BPA must be done with extreme care and wherever possible GIC should be the choice of cement. ${ }^{9}$

An in vivo study was conducted on patients wearing vacuum-formed and Hawley retainers by Akila Srinivasan Raghavan. ${ }^{10}$ They concluded that, there was an ascending growth in the salivary BPA levels in Hawley retainers processed by heat cure followed by chemically cured Hawley's retainer and greatest value in the VFRs. They have also mentioned that the exposure of BPA to the developing and growing bodies of the teenagers can be more dangerous and harmful than the exposure to the adults, as maximum of patients undergoing orthodontic treatment comprises of teenagers. The conclusion derived from their study was that the BPA leach was observed in thermoformed Biocryl retainers and fully cured Tran's bond XT orthodontic adhesive. ${ }^{10}$

Our study was in agreement with other authors evaluating leaching of Bisphenol-A from restorative resins and, although these materials are used under different situations. ${ }^{11,12}$ After the placement of resin-based composites there was an reported increase in BPA levels in saliva which was assessed by enzyme-linked immunosorbent assay methods. When the patients gargled with water after the placement of composite, it has observed that the BPA levels in saliva returned to its pretreatment levels within 24 hours. Resin-based composites 
were considered the most widely used restorative material. There was increase in the usage of composite restorations than the amalgam restorations by 2006.12

There are some methods to reduce leaching of Bispenol-A from adhesive includes removal of excess adhesive before curing, use of Bisphenol-A free adhesive and ensuring complete curing of resin.

\section{CONCLUSIONS}

After 24 hrs of exposure, adhesive \& twin block group showed significant Bisphenol-A release while twin block group showed Bisphenol-A release after 7 days exposure. So, it can be concluded from this study that BPA had leached from both heat cured acrylic resin and Transbond XT orthodontic adhesive in significant levels after $24 \mathrm{hrs}$. of exposure, while heat cure acrylic group showed BPA release till 7 days.

Financial or Other Competing Interests: None.

\section{REFERENCES}

[1] World Health Organization. Food and Agriculture Organization of the United Nations, International Food Safety Authorities Network. Bisphenol A (BPA) - current state of knowledge and future actions by WHO and FAO. Information Note No. 5, 2009.

[2] Vandenberg LN, Chahoud I, Heindel JJ, et al. Urinary, circulating, and tissue bio monitoring studies indicate widespread exposure to bisphenol A. Environ Health Perspect 2010;118(8):1055-70.
[3] Darmani H, Al-Hiyasat AS. Reproductive toxic effect of bisphenol A dimethacrylate in mice. J Biomed Mater Res 2004;69(4):637-43.

[4] Carvalho KR, Carvalho MR, Bandeeca MC, et al. Adhesive systems in orthodontics. What is new? Ortodontia SPO 2013;46:409-14.

[5] Froes-Salgado NR, Francci C. Bracket bonding in orthodontics: a review. Perspect Oral Sci 2009;1:16-20.

[6] Zanini LK, Prietsch JR, Coneicao EN, et al. Bond strength to enamel of orthodontic brackets bonded with different adhesive materials. Rev Fac Odontol Porto Alegre 1997;38:16-9.

[7] Anand MK, Majumder K, Venkateswaran S, et al. Comparison of shear bond strength of orthodontic brackets bonded using two different hydrophilic primers: an in vitro study. Indian J Dent Res 2014;25:191-6.

[8] Manabe A, Kaneko S, Numazawa S, et al. Detection of bisphenol- a in dental materials by gas chromatographymass spectrometry. Dent Mater J 2000;19(1):75-86.

[9] Moreira MR, Matos LG, de Souza ID, et al. Bisphenol a release from orthodontic adhesives measured in vitro and in vivo with gas chromatography. Am J Orthod Dentofacial Orthop 2017;151(3):477-83.

[10] Kotyk MW, Wiltshire WA. An investigation into bisphenola leaching from orthodontic materials. Angle Orthod 2014;84(3):516-20.

[11] Raghavan AS, Sathyanarayana HP, Kailasam V, et al. Comparative evaluation of salivary bisphenol A levels in patients wearing vacuum-formed and Hawley retainers: an in-vivo study. Am J Orthod Dentofacial Orthop 2017;151(3):471-76.

[12] Kingman A, Hyman J, Masten SA, et al. Bisphenol A and other compounds in human saliva and urine associated with the placement of composite restorations. J Am Dent Assoc 2012;143(12):1292-302. 